\title{
A WIRELESS NETWORK INFRASTRUCTURE ARCHITECTURE For RuRAL COMMUNities
}

\author{
Okoro Osahon and Edim Azom Emmanuel \\ Dept. of Computer Science, University of Calabar, Nigeria
}

\begin{abstract}
Wireless network implementation is a viable option for building network infrastructure in rural communities. Rural people lack network infrastructures for information services and socio-economic development. The aim of this study was to develop a wireless network infrastructure architecture for network services to rural dwellers. A user-centered approach was applied in the study and a wireless network infrastructure was designed and deployed to cover five rural locations. Data was collected and analyzed to assess the performance of the network facilities. The results shows that the system had been performing adequately without any downtime with an average of 200 users per month and the quality of service has remained high. The transmit/receive rate of 300Mbps was thrice as fast as the normal Ethernet transmit/receive specification with an average throughput of 1 Mbps. The multiple output/multiple input (MIMO) point-to-multipoint network design increased the network throughput and the quality of service experienced by the users.
\end{abstract}

\section{KEYWORDS}

Wifi-based Rural Extension, Wireless Fidelity(WiFi), Rural Community, Internet, Network Architecture.

\section{INTRODUCTION}

Wireless network refers to a form of computer communication that involves the exchange of data wirelessly between network nodes. The network nodes consist of networking devices and enddevices within the network coverage. These networking devices perform routing and switching of data from one end-device to the other. The infrastructure mode of setup of these networking devices to connect all end-devices within an area/domain is what constitute the network architecture. The rural community is any settlement that is under developed in terms of modern amenities. It is faced with several challenges such as low level of education, health care issues, lack of security and other social amenities. Recently, most predominant computing devices you often find in such communities are mobile phones used basically for voice communication and not for high data traffic because of the high usage cost [1].

Voice communication is the transfer of voice packet from one mobile device to the other using GSM technologies. Global System for Mobile (GSM) Communications standard describes a circuit-switched optimized for full duplex voice telephony. Over the years, GSM has evolved from circuit-switched voice communication to include Circuit-switched data communications via GPRS (General Packet Radio Services) and EDGE (Enhanced Data rate GSM Evolution or EGPRS). The size of bandwidth or transmitted data per second have been used to standardize these technologies using the second, third and fourth generations $(2 \mathrm{G}, 3 \mathrm{G}, 4 \mathrm{G})$ technologies. The 
greater the corresponding number, the larger the amount of bandwidth or data transmission available on each network technologies [2].

High standard technologies with large of data transmission will enhance the implementation of applications with large data transmission requirements such as telemedicine, e-learning and esurveillance. High data capacity usually comes at a cost that is the reason why they are often deployed in urban communities but seldom seen in the rural communities because of cost of investment and the user density. Return on investment has motivated these GSM companies and major Wireless Internet Service Provider (WISP) investors to concentrate their high speed wireless network in the metropolitan cities of the country [3].

Hence cost as a major factor has limited the rural areas from benefitting from these current trends taking place in the urban areas. Another factor that has contributed to the high cost of wireless network implemented in the rural areas is the lack or epileptic electric power supply from the national grid to the rural dwellers. This has added extra cost because, for the network to remain reliable and readily available, developers had to introduce alternative source of power, such as diesel/petrol generators which inevitably leads to increase in recurring cost. Hence for an economically viable high-throughput network in a rural community, it is important to consider the deployment of small per-user setup with minimal recurring cost [1].

The disadvantage of this network is that resources such as free medical healthcare information that can be delivered via this network are eluding the reach of people living in the rural area. The objective of this study was to deploy a cost effective wireless network with good performance, render good quality of service to users in rural communities. This study considered five rural locations or settlements that include: AzuiyiUdene, Ezza, Ntezi Abba, Ezzambo and Ishieke, all in Nigeria. Setting up an affordable wireless network for Internet services on these locations could serve as a model for providing Internet services to other rural communities in Nigeria. In the process of designing the wireless network attempt was made to modify the Wifi-based Rural Extension architecture described in [1].

The modification or enhancement will improve the quality of network performance and quality of service rendered to the users. This is because the proposed architecture will reduce interference from the natural obstacles within the environment and the signal strength will be enhanced. The architectural design for the proposed wireless network was broken into three (3) layers namely: Core layer Distribution layer and Access layers [4]. At the distribution layer, open shortest path first (OSPF) algorithm was used to route traffic from each location to the central router while Ethernet over internet over internet protocol (EoIP) was used to create tunnels to each location. At the access layer, the point to multipoint (PtMP) link suggested by [1] was modified by placing indoor access points in homes and tightly clustered buildings. Thereby introduction high throughput to the end-users through stronger signal strength and quality.

\section{LITERATURE REVIEW}

Building a robust network infrastructure is usually not an easy task. It is surrounding with both internal and external factors. Internal factors such as technical knowhow of the group that is to design and manage/maintain the network after deployment, and security measures taken to safeguard equipment against failures. External factors such as government regulations and RF pollution (interference) over long distance, the topography of the environment and external 
vandals. These factors were considered in this study during the design and deployment of the enhanced Wifi-based Rural Extension network architecture.

\subsection{NETWORK INFRASTRUCTURE AND RURAL COMMUNITIES}

The rural communities are considered as not viable markets for deployment of network infrastructure is meant for large telecommunication companies due to the enormous capital needed to build it [5]. This makes the risk involved. In rural communities some of the factors that discourages the GSM investors are non-uniformity in purchase of prepaid airtime throughout the year, low income per head and low population density $[6,7]$. The non-uniformity in purchase of prepaid airtime is a phenomenon that discourages sales forecast of any corporation. Revenue generated will be very difficult to estimate. In most rural settlements, family houses and that of close relatives are usually clustered around each other. Young adults in a quest to obtain a better standard of living, move to the urban settlements to either further their education or get a good paying job. As a result, these clusters of homes are mostly occupied by the aged parents and old people. This leads to a low population density and low income per head.

The pre-existing telecommunication infrastructures are not evenly distributed to satisfy the general public. Internet connectivity in developing countries is very low as compared to the developed countries and the concentration is usually among the wealthy urban communities in developing countries [8]. Cost of deployment has made the distribution of telecommunication infrastructure favor these urban communities with relatively wealthier settlers, and at the same time causing an uneven distribution of the existing infrastructure [9]. Other factors that also contribute to high cost of network deployment are government regulations, leased-line cost and international connectivity. As a result, these factors led to deployment of network infrastructures with limited data capacity, high places and low service demands.

For private investors to tackle the problem of low population density and high deployment cost in rural communities there is therefore the need to revisit the pre-existing network infrastructure as a whole. Recent improvement on Wireless Local Area Network (WLAN) technologies has led to a sustainable wireless diffusion in the rural areas of the developing countries. Such technologies have led to building networks with relatively cheap equipment that inevitably leads to low cost of deployment. Wireless technologies are not subject to the same economies of scale compared to the traditional wire line technologies. As a result, wireless infrastructure can be built by incorporating several actors such as computer programmers, network developers, sustainable energy engineers etc. throughout the development stage and thereby making the network closely knit to local context/community needs.

\subsection{Wireless Network TeChNOLOGIES For RURAL COMMUNities}

Voice communication with voice-based applications that provides both global internet content and region specific information for areas with low-literacy has been a major attraction for developing countries [10,11]. These applications range from micro-gaming console to micropayment applications. The common wireless network for rural communities is the Global System for Mobile Communication (GSM) network. This GSM networks work with technologies such as Enhanced Data from GSM Environment (EDGE), Universal Mobile Telecommunication System (UMTS), General Packet Radio System (GPRS) and High-Speed Circuit-Switched Data (HSCSD) [2]. Basically the use of telecommunication tools in developed countries is to access 
information and political freedom but indigenous customs affects the way this technology is appropriated [7]. This simply means that there is a significant influence in the appropriation of these technologies to the norms and customs in the environment. Users of these technologies in rural communities experience low quality of service that is associated with these technologies.

Most voice application e.g. gtalk and skype use a third-party remote server on the Internet to manage voice communication and since the network deployment uses one gateway to the Internet a bottleneck will occur when there are multiple request to the server. This simply means communication between two villagers will require access to this server first before passing the signal to the other. The Wireless Fidelity (Wi-Fi) technology was initially introduced to connect computers within a limited space wirelessly, but it has evolved in a somewhat accidental way by taking evolutionary path not envisioned by its creators [12]. This service has extended to devices in public places, and equipment vendors/wireless enthusiast have upgraded the technology to accommodate long distant devices using the point-to-point communication.

\subsection{NETWORK INFRASTRUCTURE DEPLOYMENTS IN RURAL COMMUNITIES}

Current innovation in the 802.11n has enhanced the throughput of wireless infrastructure to nearly $200 \mathrm{Mbps}$ which is twice as fast as the fast Ethernet of 100Mbps. Innovation such as the MIMO (Multiple input, Multiple output) works by sending multiple signal with different data set via different path. With the new Wifi alliance equipment manufactures now manufacture wireless access points and laptops with 802.1 in complaint wireless cards. All wireless local area network (WLAN) computer communication in the $2.4,3.6,5$ and $60 \mathrm{GHz}$ frequency bands are all grouped into the IEEE 802.11 protocol stack [13]. The protocol consists of a set of media access control (MAC) and physical layer (PHY) specifications [14]. To manage collision in a broadcast multiaccess (BMA) network, 802.11 defined the simple-stop-and-wait protocol. Implying that on the advent of any collision, both senders will wait at different time span before resending. This resulted to increase in propagation delay in long distance network [15]. This is a challenge that need to be handled when using the 802.11 MAC Protocol for building wireless networks in rural communities.

In an attempt to reduce the shortcomings of the 802.11 MAC protocols,[16] designed and implemented the WiLDNet to handle interconnection of rural vision centers network. WiLDNet is a TDMA-based MAC protocol with adaptive loss-recovery mechanism. With WiLDNet as an efficient wireless network put in place, other challenges that one will need to resolve in the rural communities in order to enhance the efficiency and the performance of the network include provision of locally trained technicians, maintenance personnel, and adequate power supply backup using solar cells [15]. WiLDNet and backup power supply was considered as a viable network deployment for sustainable rural network. The rural community networks that were built with WiLDNet and backup power supply alternative include: Aravind telemedicine and AirJaldi network both in India [15].

The Wifi-based Rural Extension (WIRE) Wireless architecture network[1] is another efficient technology infrastructure for providing wireless network in rural communities. But Wifi-based Long Distance (WiLDNet) described in[16] and the Wifi-based Rural Extension (WIRE) Wireless architecture networks[1] experienced connectivity issues despite the input throughput recorded. This is because the end-devices own by the rural dwellers can only communicate effectively within a limited radius. Interference from trees and other obvious obstacles attenuates the weak wireless signals from these devices to the remote base stations. The proposed enhanced 
Wifi-based Rural Extension (WIRE) Wireless architecture in this studyis designed and implemented to reduce the effect of attenuation and also improved signal propagation. This will increase the quality of service offered to the users.

WiRE[1] is an extension of WiLDNet[16]. WiLD was developed using WiLD MAC protocol to address the limitation of 802.11 over long distance transmission-links of two network nodes with unequal packet transmission sensing capability thereby leading to high packet collision rates. WiLD MAC uses fixed time-slot approach between end-points and replaces the stock 802.11 stop-and-wait protocol with a sliding-window based flow-control approach. But over longdistance link, its' performance showed significant lower throughput. Hence, WiLDMAC was further modified by replacing the fixed time-slot with adaptive time-slots and tagged "JazzyMAC" which is now referred to as WiRE[1].

The aim of WiRE[1] was to employ adaptive time-slots in the TDMA-based protocol which continuously vary with traffic demand. The WiRE network architecture gave little consideration to rural communities that are less densely populated and with natural obstacles such as tree vegetation and the settlements (end-users) that were sparsely distributed. WiRE architecture [1] used out-door access points in high rise towers/buildings for the point-to-multipoint links. This resulted to huge signal losses in some areas as a result of the tree vegetation within the rural settlements and distance between the users and the out-door access points located on towers.

The Wifi-based Rural Extension (WIRE) Wireless architecture network described in [1]was modified and enhanced further in this study by setting up point-to-multipoint links between the Base stations and the user access points. Implying that, the access points were no longer situated at the base stations but closer to the users. The trade-off was to increase the number of access points. This was possible because these access points are relatively cheap and off-the shelf devices, the trade-off could be accommodated.

This study presents the enhance-WiRE, where the point-to-multipoint network is replaced with a point-to-point/multipoint network (P2PMP). The reason is to move the access points at the high tower or base station and place them closer to the end users.

\section{RESEARCH METHOD}

The study applied a user-centered approach in the design of the wireless network architecture and the implementation of the network in the community. A survey approach was later used to ascertain from the users the effectiveness of the rural wireless architecture deployed in the communities. The study was divided into three phases namely: network specification, network design and implementation, and network validation. Each phase consisted of other activities. The network specification process was carried out with the following activities: feasibility study; requirement elicitation and analysis; requirement specification and requirement validation. During the feasibility study, five communities in Nigeria were surveyed and these include: AzuiyiUdene, Ezza, Ntezi Abba, Ezzamgbo and Ishieke communities to study the user environment and to find out the nature of the settlement structures and how the settlements are clustered together so that we could find out where to place the network access points.

During the requirement elicitation/analysis activity,wireless mesh network structure was designed and used to map out ten (10) different paths for wireless connection. The distance of each wireless connection path was evaluated by using the "Ruler tool" in googleearth software to 
analyse the line of sight. An oral interview was further conducted at each community site to obtain data such as level of power supply, GSM network availability and the security situation. At the requirement specification activity, several conditions that were needed to be met in the design include the following: improved network uptime, reliability in the network services, high data security in the network, networkscalability, and fast network recovery rate in case of any downtime that may occur. Measures were taken in order to design the network in a way that it can deliver a high throughput, secure data and readily be available. According to [13], the 802.11n chipsets and devices offer higher bandwidth, as well as improved security and quality of service.

In view of this, a set of Ubiquity equipment with 802.11n chipset were surveyed in order to gather the necessary requirements specification. Based on the requirement specification, a template containing criteria to use for requirement validation task was created. The requirement validation involves the following: Scalability check, Availability check, Security check and manageability check, error and inconsistency checks, and ambiguity checks. These checks were conducted and corrections were effected. The Cisco design model for Hierarchical network design was adopted during the network design and implementation stage. The design of the proposed enhanced Wifi-based Rural Extension Architecture (WiRE) was organized in a layered approach. This implies that the enhanced WiRE network was broken into the Core Layer, Distribution Layer and Access Layer.

The core layer is responsible for handling large amount of data traffic and also ensure that the transmission is reliable and fast. The main purpose of the network's core layer is to switch traffic as fast as possible [4]. A 2.6 diameter dish Vsat antenna was used to connect to the Internet. The Vsat modem was connected to a router where bandwidth hshaping and an authentication page was setup. A radius server and user database was then configured for authentication while the router monitors the access control using the radius server. The equipment used were: Vsat equipment (outdoor/indoor), a Router (Mikrotik Router Board 2011L) and a Radius Server (MySQL, MyPhPAdmin, Dalaradius).

The distribution layer, also known as workgroup layer, is responsible for the routing, filtering and WAN access of packets within the network and the core [4]. It is the linkage between the core and access layer. This later was further divided into the hardware and software section. The hardware section covers the physical mesh connectivity of the five locations using ubiquity Nano Beam M5 MIMO radios to connect each community wirelessly (i.e. Point-to-Point connection) and Mikrotik 750GL routers to ensure each remote broadcast are properly bounded. While the software section involved the configuration of open shortest path first algorithm (OSPF) on the 750GL routers to calculate the best path a packet can follow at any time. After selecting the best path, a packet will follow from one location to the next, a virtual funnel was also configured to connect each location to the main core router.

At the access layer implementation stage, we deploy a Point-multipoint uplink using a ubiquit I Nano Station M5(Access point) at each base station and a ubiquity Nano Station M5 Loco with a Unifi UAP-PRO $2.4 \mathrm{Ghz}$ Access point in all the selected points where the wireless signal is intended to cover. Each location where this setup was installed, was considered as the hotspot. The equipment deployed at this point include: Ubiquity M5 Loco: Uplink for each hotspot to pick from, Ubiquity M5 Loco: Uplink for each hotspot, Ubiquity UniFi: Access point installed at every hotspot. The controller software shipped with the Ubiquity UniFi, was used to achieve a wireless distribution system where every hotspot share the same unique service set identifier (SSID). 
During the network validation process, network devices were used to test for connectivity in all five locations and to ensure that the network meets the required target in all the locations. The devices used include smart phones, Techno M9 to be precise, Samsung galaxy tab 4 and HP laptop. The next stage was to place filters on the radius server that will keep track of all the activities taking place on the network. After the deployment and network test the users were allowed to use the network to have access to Internet services. A questionnaire was designed and distributed to the users in the communities in order to have users' assessment of the wireless network system.

\section{RESUlts AND DisCUSSION}

During the study, different methods and tools were used collect and analyse data during the design and implementation of the wireless network. The analysis data and results are presented in the next sections.

\subsection{NeTWORK REQUiREMENT DATa ANALysis}

In order to elicit and analyse the network requirement(s), a site survey was conducted using tools such as a magnetic compass, binoculars, 14-pixel sonny digital camera and writing materials. Using the magnetic compass, the exact geo-coordinates of the sites were obtained (Table 1). The coordinates were keyed into the google earth software in order to map out the wireless signal path and also spot the obvious obstacle (Azuiyi Udene Mountain) along the line of sight (figure1). Each yellow pin in figure1 signifies a location and the blue/red lines signify the wireless pilot link.

Table 1: Geo-coordinates of the five sites surveyed

\begin{tabular}{|c|l|l|}
\hline S/N & Site & Geo-coordinates \\
\hline 1 & AzuiyiUdene & $6^{0} 19^{\prime} 25.11^{\prime \prime} \mathrm{N}, 8^{0} 07^{\prime} 39.92^{\prime \prime} \mathrm{E}$ \\
2 & Ezza & $6^{0} 19^{\prime} 15.31^{\prime \prime} \mathrm{N}, 8^{0} 05^{\prime} 05.10^{\prime \prime} \mathrm{E}$ \\
3 & Ntezi Abba & $6^{0} 19^{\prime} 16.57^{\prime \prime} \mathrm{N}, 8^{0} 05^{\prime} 31.62^{\prime \prime} \mathrm{E}$ \\
4 & Ezzamgbo & $6^{0} 23^{\prime} 57.28^{\prime \prime} \mathrm{N}, 8^{0} 00^{\prime} 43.79^{\prime \prime} \mathrm{E}$ \\
5 & Ishieke & $6^{0} 22^{\prime} 38.21^{\prime \prime} \mathrm{N}, 8^{0} 02^{\prime} 34.28^{\prime \prime} \mathrm{E}$ \\
\hline
\end{tabular}

The Google-earth application was also used to map out ten (10) point-to-point wireless route in order to obtain full-mesh connectivity between the five sites. Table 2 shows the various routes and their relative distances.

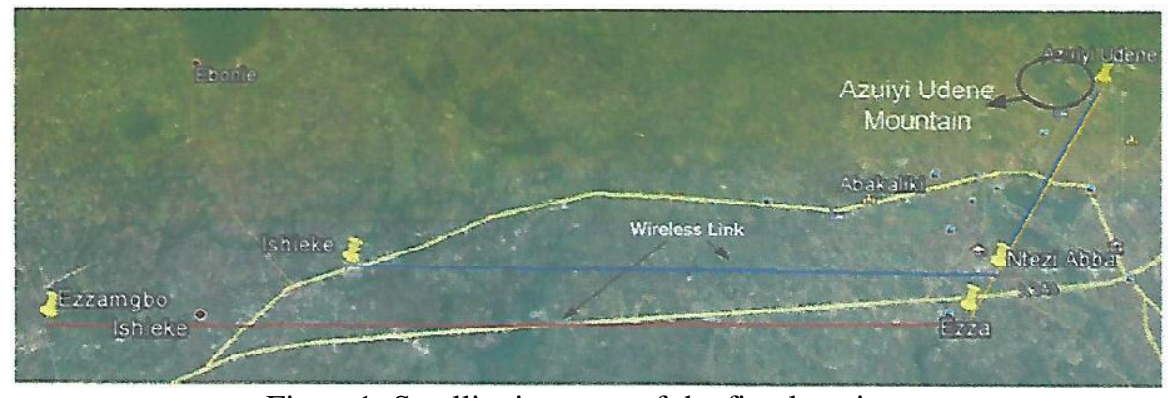

Figure1: Satellite imagery of the five locations 
In table 2, the route between AzuiyiUdene to Ntezi Abba is $3.9 \mathrm{~km}$ and between AzuiyiUdene to Ezza is $4.73 \mathrm{~km}$. The links "AzuiyiUdene to Ishieke" and "AzuiyiUdene to Ezzamgbo" could not be achieved because of the obvious obstacle on their line of sight (AzuiyiUdene Mountain). So, a partial mesh network was adopted during the design and implemented. At the network requirement specification stage, a survey of the Ubiquiti $802.11 \mathrm{~m}$ chipset wireless radios was conducted for secondary data. The radios were categorized into $5.8 \mathrm{GHz}$ spec and $2.4 \mathrm{GHz}$ spec. Table 3 shows the $5.8 \mathrm{GHz}$ radios surveyed while Table 4 presents the $2.4 \mathrm{Ghz}$ radio surveyed. From the survey of the Ubiquity $802.11 \mathrm{n}$ chip set, the Ubiquity NanoBeamM5 was seen to have a high processing speed of 560Mhz (Table 3) and built with a wireless standard of IEEE 802.11n.

It simply means that it could perform multiple input multiple output (MIMO) signal propagation at a high speed thereby increasing throughout over the proposed point-to-point link. Within a community, the Ubiquiti Nano station M5 and Loco M5 both support IEEE 802.11n with a chipset of $400 \mathrm{Mhz}$ processing speed. These were chosen for implementation.

Table 2: Point-to-point route and relative distance

\begin{tabular}{|l|l|l|}
\hline S/N & Locations & Distance (in Km) \\
\hline 1 & AzuiyiUdene to Ntezi Abba & 3.9 \\
\hline 2 & AzuiyiUdene to Ezza & 4.73 \\
\hline 3 & AzuiyiUdene to Ishieke & 11.11 \\
\hline 4 & AzuiyiUdene to Ezzamgbo & 14.81 \\
\hline 5 & EzzatoNtezi Abba & 0.88 \\
\hline 6 & Ezza to Ishieke & 7.81 \\
\hline 7 & Ezza to Ezzamgbo & 11.40 \\
\hline 8 & Ntezi Abba to Ishieke & 8.34 \\
\hline 9 & Ntezi Abba to Ezzamgbo & 11.91 \\
\hline 10 & Ezzamgbo to Ishieke & 3.74 \\
\hline
\end{tabular}


International Journal of Computer Science \& Information Technology (IJCSIT) Vol 9, No 3, June 2017

Table 3: List of 802.11n chipsets and devices surveyed [17]

\begin{tabular}{|c|c|c|c|c|c|c|c|c|c|}
\hline $\mathrm{S} / \mathrm{N}$ & Equipment & Standard & Chipset & $\begin{array}{l}\text { Operating } \\
\text { frequency }\end{array}$ & $\begin{array}{l}\text { Max. } \\
\text { output } \\
\text { power }\end{array}$ & $\begin{array}{l}\text { Receiver } \\
\text { sensitivity }\end{array}$ & Antenna & 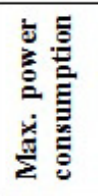 & $\begin{array}{l}\text { Max } \\
\text { power }\end{array}$ \\
\hline 1 & \begin{tabular}{|l|} 
Ubiquiti \\
Nanostation \\
M5
\end{tabular} & $\begin{array}{l}\text { IEEE } \\
802.11 \mathrm{a}, \\
\text { IEEE } \\
802.11 \mathrm{n} \\
\text { IEEE } \\
802.3 \mathrm{u}\end{array}$ & \begin{tabular}{|l|} 
Atheros \\
MIPS \\
$24 \mathrm{KC}$ \\
$400 \mathrm{MHz}$ \\
\end{tabular} & $\begin{array}{l}5170 \mathrm{MHz} \\
- \\
5875 \mathrm{MHz}\end{array}$ & $\begin{array}{l}22 \mathrm{dBm} \\
@ \\
54 \mathrm{Mbps}\end{array}$ & $\begin{array}{l}-75 \mathrm{dBm} \\
@ \\
54 \mathrm{Mbps}\end{array}$ & $\begin{array}{l}\text { Build-in, } \\
2 \times 2 \\
\text { MIMO14d } \\
\text { Bi }\end{array}$ & $8 \mathrm{~W}$ & $\begin{array}{l}\text { PoE } \\
15 \mathrm{~V}\end{array}$ \\
\hline 2 & \begin{tabular}{|l|} 
Ubiquiti \\
Nanostation \\
Eoco M5
\end{tabular} & $\begin{array}{l}\text { IEEE } \\
802.11 \mathrm{a}, \\
\text { IEEE } \\
802.11 \mathrm{n} \\
\text { IEEE } \\
802.3 \mathrm{u}\end{array}$ & \begin{tabular}{|l|} 
Atheros \\
MIPS \\
$24 \mathrm{KC}$ \\
$400 \mathrm{MHz}$ \\
\end{tabular} & $\begin{array}{l}5170 \mathrm{MHz} \\
- \\
5875 \mathrm{MHz}\end{array}$ & $\begin{array}{l}22 \mathrm{dBm} \\
@ \\
54 \mathrm{Mbps}\end{array}$ & $\begin{array}{l}-75 \mathrm{dBm} \\
@ \\
54 \mathrm{Mbps}\end{array}$ & $\begin{array}{l}\text { Build-in, } \\
2 \times 2 \\
\text { MIMO } 13 \\
\text { dBi }\end{array}$ & $8 \mathrm{~W}$ & $\begin{array}{l}\text { PoE } \\
24 \mathrm{~V}\end{array}$ \\
\hline 3 & $\begin{array}{l}\text { Ubiquiti } \\
\text { NanoBeam } \\
\text { M5 }\end{array}$ & $\begin{array}{l}\text { IEEE } \\
802.11 \mathrm{a} / \mathrm{n}\end{array}$ & \begin{tabular}{|l|} 
Atheros \\
MIPS \\
$74 \mathrm{KC}$ \\
$400 \mathrm{MHz}$ \\
\end{tabular} & $\begin{array}{l}5170 \mathrm{MHz} \\
- \\
5875 \mathrm{MHz}\end{array}$ & & & $\begin{array}{l}\text { Build-in, } \\
22 \mathrm{dBi}\end{array}$ & $6 \mathrm{~W}$ & $\begin{array}{l}\text { Poe } \\
24 \mathrm{~V}\end{array}$ \\
\hline 4 & $\begin{array}{l}\text { Ubiquiti } \\
\text { NanoBridge } \\
\text { M5 MIMO } \\
\text { (NBM5-22) }\end{array}$ & $\begin{array}{l}\text { IEEE } \\
802.11 \mathrm{a}, \\
\text { IEEE } \\
802.3 \mathrm{u}\end{array}$ & \begin{tabular}{|l|} 
Atheros \\
MIPS \\
$24 \mathrm{KC}$ \\
$400 \mathrm{MHz}$
\end{tabular} & $\begin{array}{l}5170 \mathrm{MHz} \\
- \\
5875 \mathrm{MHz}\end{array}$ & & & $\begin{array}{l}\text { Build-in, } \\
22 \mathrm{dBi}\end{array}$ & $5.5 \mathrm{~W}$ & $\begin{array}{l}\text { PoE } \\
24 \mathrm{~V}\end{array}$ \\
\hline
\end{tabular}

The Advanced Traffic Management Specification for the UniFiUAP Pro access point (Table 4) shows that it handles over 200 concurrent clients. While table 5 (Supported Data Rates) indicates that the 802.11n inbuilt technology in the UniFiUAP Pro Access point can support data rates between $6.5 \mathrm{Mbps}$ and $450 \mathrm{Mbps}$. These two properties (number of concurrent clients and supported data rates) supports the choice of this device as the access point for the implementation of the architectural design in this study.

Table 4: Advanced Traffic Management

\begin{tabular}{|l|l|}
\hline VLAN & 802.IQ \\
\hline Advanced QoS & Per-User Rate Limiting \\
\hline Guest traffic isolation & Supported \\
\hline WMM & $\begin{array}{l}\text { Voice, Video, Best effort, and } \\
\text { Background }\end{array}$ \\
\hline Concurrent Clients & $200+$ \\
\hline
\end{tabular}

Table 5: Advanced Traffic Management

\begin{tabular}{|l|l|}
\hline $802.11 \mathrm{a}$ & $6,9,12,18,24,36,48,54 \mathrm{Mbps}$ \\
\hline $802.11 \mathrm{n}$ & $6.5 \mathrm{Mbps}$ to $450 \mathrm{Mbps}$ (MCSO-MCS23, HT 20/40) \\
\hline $802.11 \mathrm{~b}$ & $1,2,5.5,11 \mathrm{Mbps}$ \\
\hline $802.11 \mathrm{~g}$ & $6,9,12,18,24,36,48,54 \mathrm{Mbps}$ \\
\hline
\end{tabular}


Table 6: Wireless Access Point [17]

\begin{tabular}{|c|c|}
\hline \multicolumn{2}{|c|}{ The Wireless Access PointUbiquiti Unifi UAP-PRO 2.4/5Ghz } \\
\hline Requirement & Specification \\
\hline Networking Interface (Mbps) & $2 \times 10 / 100 / 1000$ Ethemet Ports \\
\hline Buttons & \begin{tabular}{|l|} 
Reset \\
\end{tabular} \\
\hline \multirow[t]{2}{*}{ Antennas } & $\begin{array}{l}2.4 \mathrm{GHz}-3 \text { integrated (supports } 3 \times 3 \mathrm{MIMO} \\
\text { WITH Spatial Diversity), }\end{array}$ \\
\hline & $\begin{array}{l}5 \mathrm{GHz}-2 \text { integrated (Supports } 2 \times 2 \mathrm{MIMO} \text { with } \\
\text { Spatial Diversity) }\end{array}$ \\
\hline WiFi Standards & $802.11 \mathrm{a} / \mathrm{b} / \mathrm{g} / \mathrm{n}$ \\
\hline Power Method & $\begin{array}{l}\text { Passive power over ethemet (48V), } \\
802.3 \text { af Supported }\end{array}$ \\
\hline \multirow[t]{2}{*}{ Power Supply } & $48 \mathrm{~V}$, \\
\hline & 0.5A PoE Adapter (Included) \\
\hline Max. Power consumption & $12 \mathrm{~W}$ \\
\hline Maximum TX Power & $2.4 \mathrm{GHz}-30 \mathrm{dBm}, 5 \mathrm{GHz}-22 \mathrm{dBm}$ \\
\hline BSSID & Up to Four Per Radio \\
\hline Dimensions & $200 \times 200 \times 36.5 \mathrm{~mm}$ \\
\hline Weight & $298 \mathrm{~g}$ (358g with Mounting Kits) \\
\hline Power Save & Supported \\
\hline Wireless Security & $\begin{array}{l}\text { WEP,WPA-PSK, WPA-TKIP,WPA2 AES, } \\
802.11 \mathrm{i}\end{array}$ \\
\hline Certifications & $\mathrm{CE}, \mathrm{ECC}, \mathrm{IC}$ \\
\hline Mounting & Wall/Ceiling (Kits Included) \\
\hline Operating Temperature & $-10 \div 70^{\circ} \mathrm{C}$ \\
\hline Operating Humidity & $5 \div 80 \%$ Condensing \\
\hline
\end{tabular}

Table 4 presents the specification for Ubiquiti UniFiUAP Pro wireless access point. The specifications that were considered in this study include the antenna diversity, Wi-Fi standard, and power supply.

This device can carry out a minimum of 2x2 MIMO spatial diversity and complaint with $802.11 \mathrm{n}$ WiFi standard. It consumes a direct current of $0.5 \mathrm{~A}$ with a voltage of $48 \mathrm{~V}$ and $12 \mathrm{Watt}$.

\subsection{DESIGN OUTCOME}

Based on the cisco hierarchical layer design model and the WiFi-based Rural Extension Architecture [1], the proposed network architecture designed layers are presented next. In the design, the Core layer is structured to handle the backbone Internet and setup accounting, authentication and access control policies. The Distribution layer is to handle the Internet services to the five locations reliably and at fast speed. The Access layer is to further distribute the Internet services to users.Figure 2 shows the core layer design. A $2.4 \mathrm{~m}$ dish was installed in AzuiyiUdene site with a bandwidth of $26 \mathrm{Mbps}$ download and $4 \mathrm{Mbps}$ upload. A public IP was obtained from Internet service provider (ISP) and a captive portal was created on the mikrotik 2011L routerbox to obtain login details from the users. Each login detail will be matched with the radius server database and authentication will be granted if the user is a registered user. The user network is connected to the router through the Dink unmanaged switch. 


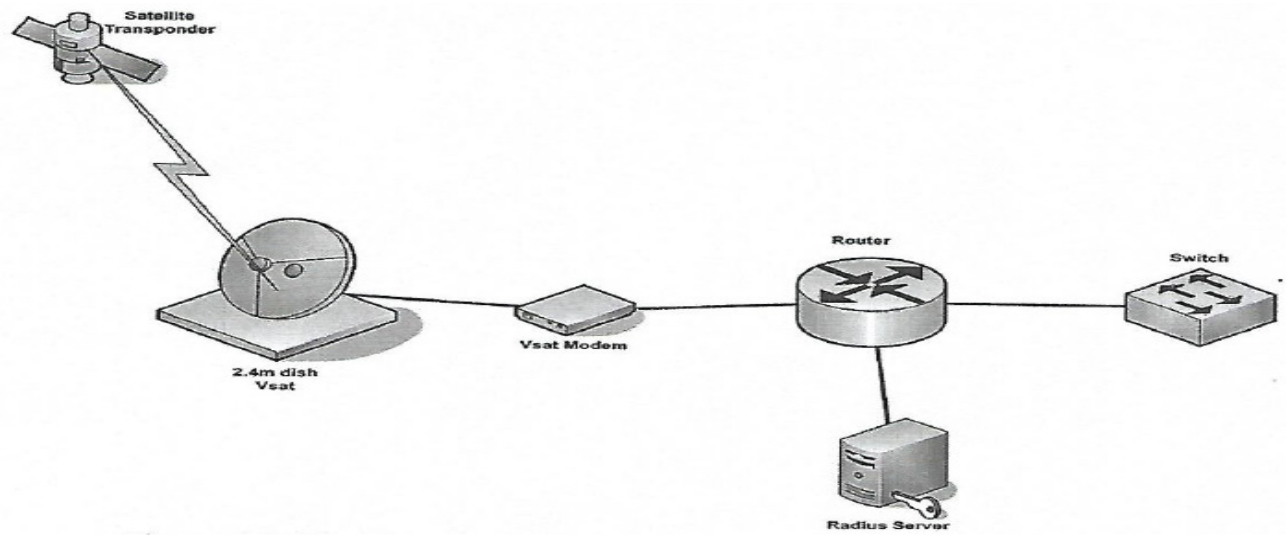

Figure2: The Core layer design

Figure 3 shows the distribution layer design. Out of the ten wireless links that were proposed during the network specification process, only eight were deployed during the implementation as a result of the obvious obstacle (AziyiUdene Mountain) blocking their line of site. The Ubiquiti NanoBeam M5 was used to shoot point-to-point links because of its MIMO technology and faster processor of 560Mhz. Amikrotikrouterbox $750 \mathrm{GL}$ was placed behind each point-to-point link. An IP address of two (2) valid hosts i.e. 10.10.10.0/30 was assigned to each point-to-point link. In the access layer design a point-to-multipoint $5.8 \mathrm{Ghz}$ wireless network was introduced (figure 4) by placing a The Open Shortest Path First (OSPF) routing protocol was configured on each Mikrotik 750GL router to introduce redundancy into the network in the event of link going down. The Ethernet Over Internet Protocol (EOIP) was configured as the layer 2 protocol that will take layer two data from the core router to each location separately. This description shows how the distribution layer design was implemented. Nanostation M5 on the various mast and a Nanostation Loco M5 at selected homes, school halls or social buildings. The Ubiquiti Unifi redistributes $2.4 \mathrm{GHz}$ wireless signals at a 600 -meter radius open space or 499 -meter radius indoor. The Ubiquiti Nanostation Loco M5 and Unifi were both connected together via a switch (in case of multiple UniFi connections) or straight-through cable between both with power over Ethernet (POE) injector to introduce full duplex connection.

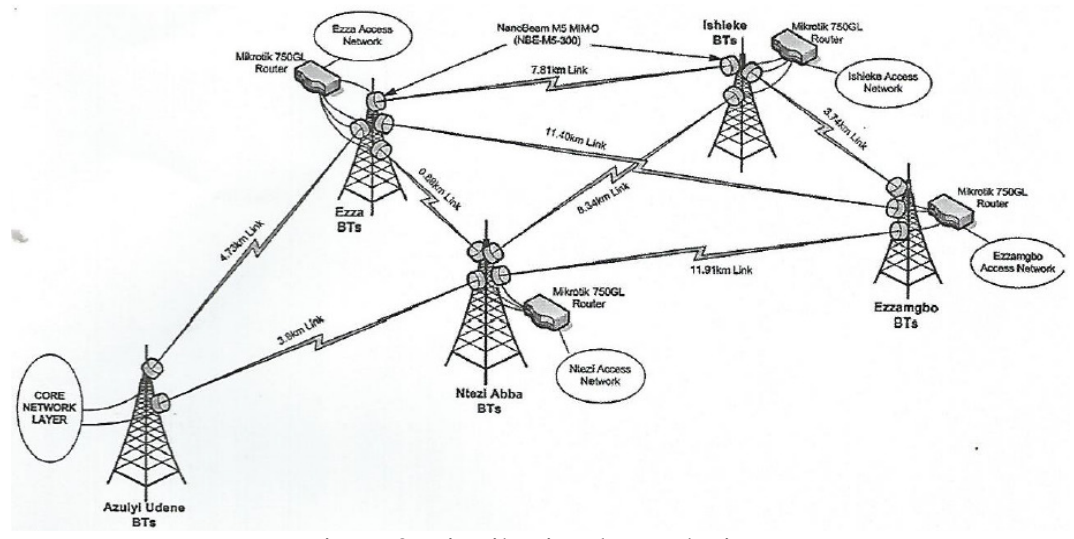

Figure3:Distribution layer design 


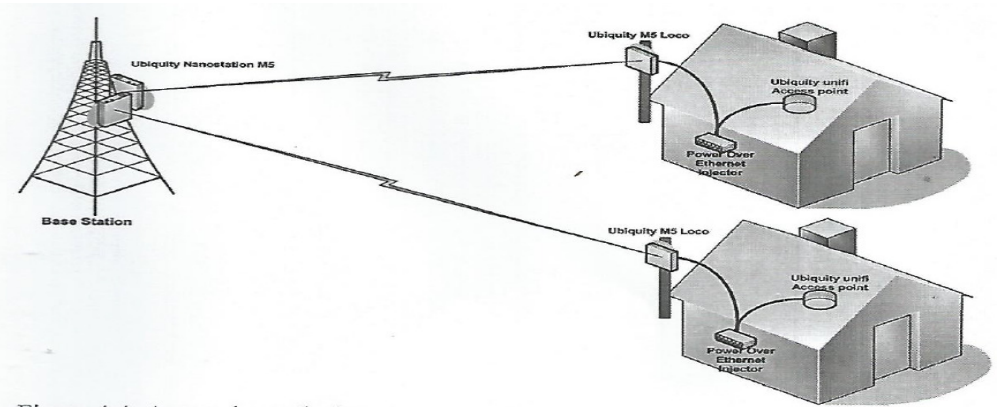

Figure4: Access layer design

Figure 5 shows the complete system architecture with all the three layers put together as a single network architecture. This shows the wireless network structure that was deployed in the communities during the study.

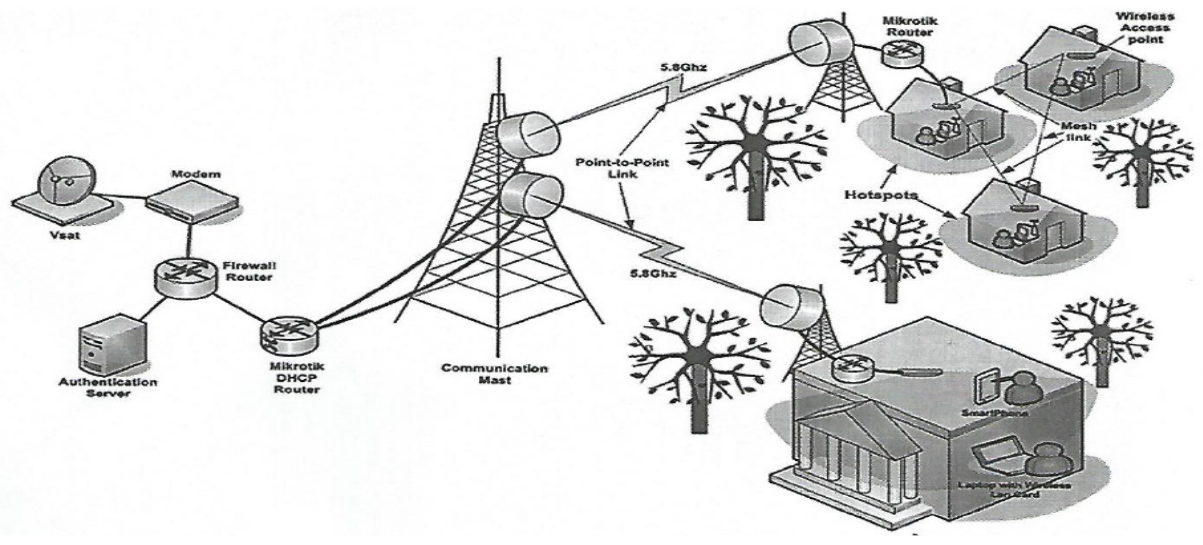

Figure5: The enhanced wireless network system Architecture

\subsection{Network Performance OUTPut}

Figure 6 and 7 shows the output display for the performance of the point to multipoint (PtMP) network at the access layer of the network implementation. The basic setting of the Nano station M5 (Figure6) shows that the wireless mode of the equipment was set to "Access point" and the network mode configured as "Bridge" implying that all traffic entering the wired (LAN) interface goes directly to the wireless (WLAN) interface. A dynamic frequency selection (DFS) of $5560 \mathrm{Mhz}$ (Channel 112) was used to transmit signals with a channel width of $40 \mathrm{Mhz}$ to mitigate interference. Special diversity chain of $2 \times 2$ was configured to reduce transmit power and increase antenna gain. With the noise floor reduced to $-92 \%$ a good air MAX quality and capacity was attained. Air MAX is an Ubiquity Time Division Multiple Access (TDMA) Proprietary protocol. It works by allowing each client send and receive data using pre-designated time slots scheduled by an intelligent AP controller (UBNT, 2013). The throughput graph (Monitor section, figure6) shows the bridge effect between the wired (LAN) and wireless (WLAN) interfaces implying that Tx in WLAN interface is same as Rx in LAN interface vise-a-vis. The graph is scaled from 0 to $3 \mathrm{Mbps}$ and an average throughput of $1.5 \mathrm{Mbps}$ was adopted as the expected throughput at the client side. The result shows that the signal quality send/received at the access layer is high. This 
will enable the users to send and receive data at very high speed and the quality of service that will be experienced by the users will be high.

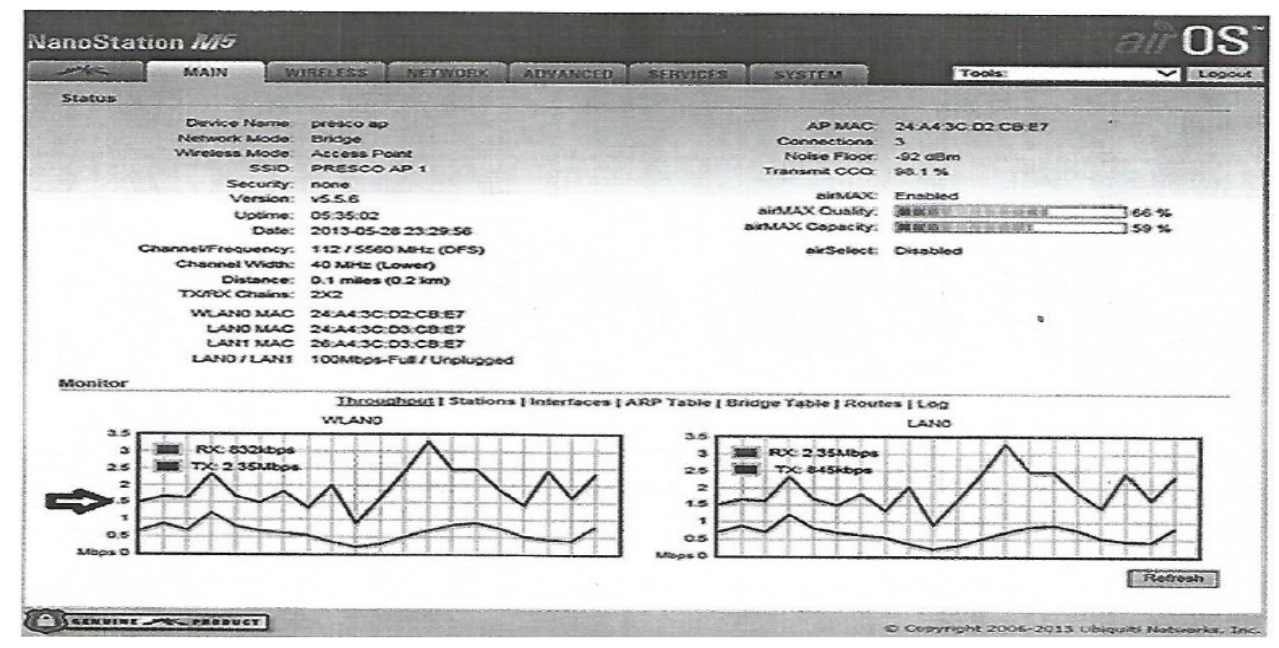

Figure 6: PtMP Access Point (Nano Station M5) Output

Figure6shows the status/monitor screen shot for the client/station equipment. A signal strength of $-60 \mathrm{dbm}$ was achieved with a noise floor of $-90 \mathrm{dbm}$. The transmit/receive $(\mathrm{Tx} / \mathrm{Rx})$ rate was $300 \mathrm{Mbps}$, which is thrice as fast as Ethernet (100Mbps). On the monitor section, an average throughput of $1 \mathrm{Mbps}$ was obtained (see the graph section of figure 6 and 7 with the pointing arrow). This shows that a loss of $0.5 \mathrm{Mbps}$ was observed on the network and the impact on the signal strength is minimal. Considering the numerous environmental obstacles such as trees, and mountains, a high path loss would have resulted relatively high data loss of over $0.5 \mathrm{Mbps}$. This explains the high amount of data transmitted to the users. A 3GB of data per month was recorded for each user of the network (see Table ). Figure 6 and 7 also shows that the air Max Quality (Quality of service protocol inbuilt on the radios) of the radios were above $50 \%$ level of performance. The network rendered high performance level and quality of service.

The network output shows that $100 \mathrm{Mbps}$ Ethernet speed from the base station (BTs) entering a $300 \mathrm{Mbps}$ wireless network is efficiently delivered to the $100 \mathrm{Mbps}$ Ethernet speed at the client side which is then passed to a $2.4 \mathrm{Ghz}$ wireless access network via the Ubiquiti $2.4 \mathrm{Ghz}$ UniFi access point. A total of forty-eight (48) UniFi2.4Ghzwere connected in the five locations. The access points were simultaneously configured using the UniFi AP controller. Figure 8 shows a screenshot of the UniFi AP controller. The AP controller provides the number of clients connected to an Access point at a time (t) and the bandwidth (download/upload) each access point is currently using including the channel of $2.4 \mathrm{Ghz}$ frequency. The output in figure 8 also shows that a single access point has up to 135 users consuming a bandwidth of $40.3 \mathrm{G}$ download and $3.07 \mathrm{G}$ upload data. This proved that the $802.11 \mathrm{n}$ protocols encourages high number of users with high data traffic at relatively low setup cost compared to GSM technology [2]. The result shows high quality network performance provided by the enhanced Wifi-based rural extension wireless architecture. This indicates that that network architecture implemented is very effective. The strong signal strength means the users will experience high quality of service and it will add value to the socio-economic life of the users. Access to information and other ICT services will be easy and the users will have value for money spent. 


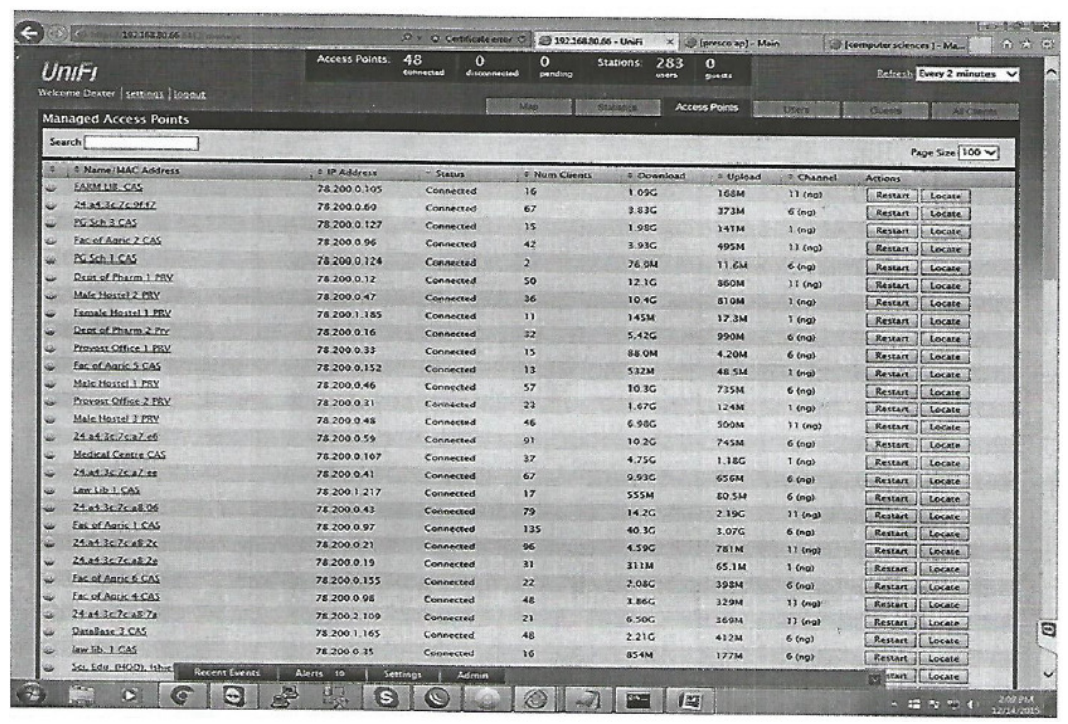

Fig 8: Screenshot of the 2.4Ghz AP Controller

Data was collected from the rural network for analysis in order to determine the number of users that connect to the Internet through the wireless network infrastructure and also to determine the amount of data used within the first eleven months of deployment. The results are shown in Table7 and 8. Since user authentication was only requested when a user intends to have access to Internet services, a lot of devices were noticed making attempt to gain access. Only the registered ones had access to the Internet services on the network. In Table 7 and 8, it shows that an average of 137 users used the wireless network per month. The average amount of data used per month was $393,933 \mathrm{Mb}$ and it is equivalent to $394 \mathrm{~GB}$ internet data used per month. This means that the average Internet data per month used by a single user is approximately $3 \mathrm{~GB}$. With a data capacity of $3 \mathrm{~GB}$ per month, an e-learning application that can run with a bandwidth of $100 \mathrm{Mb}$ daily can be provided for students and pupils in the communities. The network performance is high and of good quality.

The 3GB data access rate per user at a lower cost, shows that the network services are affordable and effective for rural community users. The study found that access points located closer to the user devices improved signal quality and enabled large number of user connectivity. The location of the access points greatly reduced the problem of signal attenuation and lost that would have been caused by obstacles within the environmental.

Table 7: Number of Users

\begin{tabular}{|l|c|}
\hline Month & No of Users \\
\hline July, 2014 & 30 \\
\hline Aug, 2014 & 95 \\
\hline Sep, 2014 & 106 \\
\hline Oct, 2014 & 67 \\
\hline Nov, 2014 & 106 \\
\hline Dec, 2014 & 146 \\
\hline Jan, 2015 & 174 \\
\hline Feb, 2015 & 169 \\
\hline Mar, 2015 & 210 \\
\hline April, 2015 & 196 \\
\hline May, 2015 & 203 \\
\hline
\end{tabular}


International Journal of Computer Science \& Information Technology (IJCSIT) Vol 9, No 3, June 2017

Table 8: Total amount of internet data used per month

\begin{tabular}{|l|c|}
\hline Month & Internet Data used (MB) \\
\hline July, 2014 & 3917.828935 \\
\hline Aug, 2014 & 90213.31487 \\
\hline Sep, 2014 & 174532.8703 \\
\hline Oct, 2014 & 298902.3684 \\
\hline Nov, 2014 & 627528.487 \\
\hline Dec, 2014 & 378357.6963 \\
\hline Jan, 2015 & 684775.3241 \\
\hline Feb, 2015 & 323542.1087 \\
\hline Mar, 2015 & 351976.2921 \\
\hline April, 2015 & 580799.3252 \\
\hline May, 2015 & 818711.3538 \\
\hline
\end{tabular}

Figure 9 shows the bar chart for the number of users who used the wireless network per month as shown in table 7. From the bar chart, it is clearly shown that March 2015 recorded the highest number of users (210) while figure 10 shows the bar chart of the amount of data used by the users per month. It is noticeable from the bar chart in Figure 10 (as shown in table 8) that data used was gradually increasing as the months of the year increases. The increase in data consumption shows that the users find the network reliable and affordable. With the solar power input a network uptime from $29^{\text {th }}$ July, 2014 to $21^{\text {st }}$ May 2015 approximately eleven (11) months was recorded. Bandwidth shaping carried out on the router was $128 \mathrm{kbps}$ per user. To obtain the number of expected users, the formula shown below was applied and it resulted to 208 concurrent users.

$$
\begin{aligned}
\text { Expected number of concurrent users }= & \frac{\text { Total download in kbps }}{128} \\
& =\frac{(26 \times 1024)}{128} \\
= & 208 \text { Users }
\end{aligned}
$$

The 11 months uptime without disruptions on the network points to the fact that the architectural design of the network is reliable and secured. The network within the first year of operation has been available to the users and also manageable. The users also agreed that the quality of service they get meets their expectation.

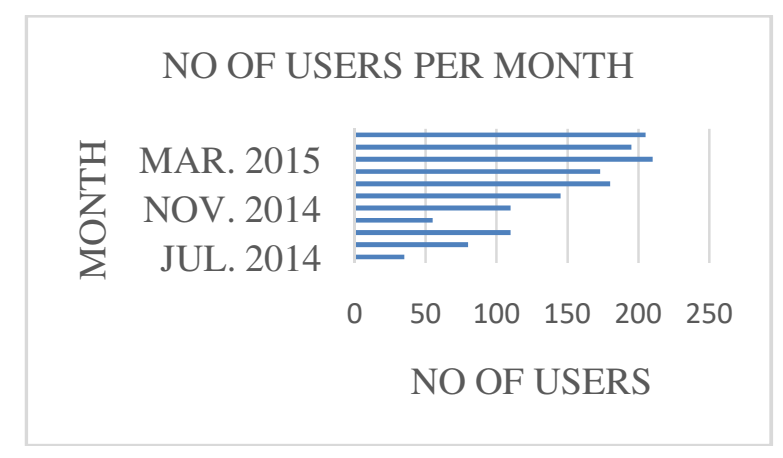

Figure 9: The number of users per month 


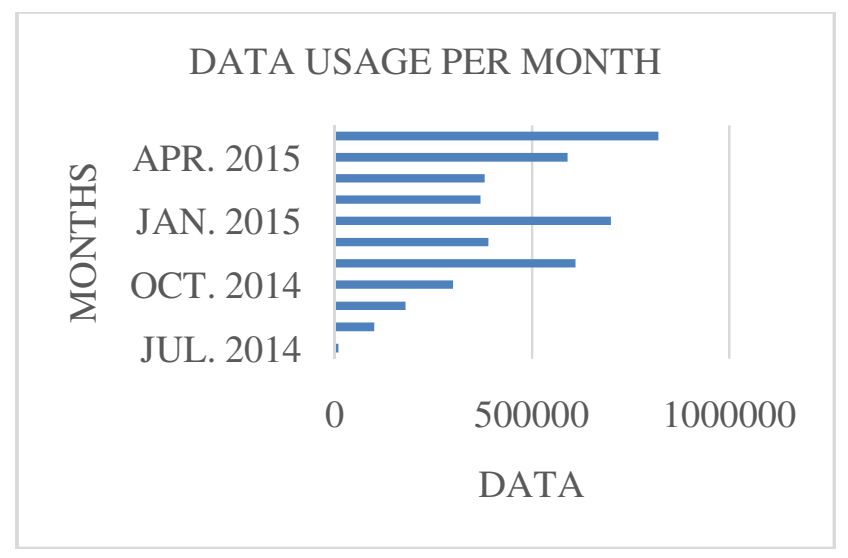

Figure 10: The amount data used per month

\subsection{NETWORK USAGE}

Questionnaires were distributed to the users in the five locations to evaluate the network performance and usage in the communities. The type of devices used in accessing the network, the kind of media platform often use and the strength of the wireless network they received compared to the GSM network in the area, are other data the questionnaire tries to find out. Demography of the Respondents - The analysis of the data collected from the 200 questionnaires distributed to the five locations was performed (Table 9). The analysis shows that majority of the users were between the ages of 25 to 39 years old (104 and 52\%). Also, 20 to 24 years old were 67 in number (33.5\%), and 40 and above where 29 in number and making $14.5 \%$ (table 9). 56.5\% of the sample population were female, while the remaining $43.5 \%$ were male. The married ones were $56 \%$ of the population, while the singles were $41 \%$ of the population and leaving the remaining $8 \%$ as the widowed.

Majority of the respondents were senior school leavers (49\%), while those educated to the University level i.e. first degree were $11 \%$ of the population, leaving the remaining $40 \%$ of those with middle level education. Out of the 200 respondents, $107(53.5 \%)$ had a source of income and $93(46.5 \%)$ were still in school i.e. students.

Table 9: Demography of Respondents

\begin{tabular}{|l|c|l|}
\hline \multicolumn{3}{|c|}{ Respondents } \\
\hline Age & Frequency & Percent \\
\hline $20-24$ & 67 & 33.5 \\
\hline $25-39$ & 104 & 52 \\
\hline 40 and above & 29 & 14.5 \\
\hline Total & $\mathbf{2 0 0}$ & $\mathbf{1 0 0}$ \\
\hline \multicolumn{3}{|c|}{ Sex of Respondents } \\
\hline Sex & Frequency & Percent \\
\hline Male & 87 & 43.5 \\
\hline Female & 113 & 56.5 \\
\hline Total & $\mathbf{2 0 0}$ & $\mathbf{1 0 0}$ \\
\hline \multicolumn{2}{|c|}{ Educational Qualification of Respondents } \\
\hline Edu. Qual & Frequency & Percent \\
\hline SSCE & 98 & 49 \\
\hline
\end{tabular}




\begin{tabular}{|l|c|l|}
\hline OND/HND & 80 & 40 \\
\hline B.Sc & 22 & 11 \\
\hline Total & $\mathbf{2 0 0}$ & $\mathbf{1 0 0}$ \\
\hline \multicolumn{2}{|c|}{ Employment Status of the Respondents } \\
\hline Employment status & Frequency & Percent \\
\hline Working class & 107 & 53.5 \\
\hline Student & 93 & 46.5 \\
\hline Total & $\mathbf{2 0 0}$ & $\mathbf{1 0 0}$ \\
\hline Location & Frequency & Percent \\
\hline AzuiyiUdene & 138 & 69 \\
\hline Ntezi Abba & 45 & 22.5 \\
\hline Ezza & 9 & 4.5 \\
\hline Ishieke & 8 & 4 \\
\hline Ezzamgbo & 19 & 9.5 \\
\hline Total & $\mathbf{2 0 0}$ & $\mathbf{1 0 0}$ \\
\hline
\end{tabular}

The distribution of the respondents (Table 9) in the five locations shows that $66(33 \%)$ of the respondents were from Ntezi Abba, 49(24.5\%) from Ezza, 35(17.5\%) from Ishieke, 31(15.5\%) from AzuiyiUdene and 19(9.5\%) from Ezzamgbo. The social media platform section (table 10) summarizes the mobile application often used by the respondents. $77(38.5 \%)$ of the respondents utilize the rural wireless network with blackberry messenger, 95(47.5\%) use the wireless network with facebook application, 11(5.5\%) use the wireless network with both twitter and Instagram while the remaining $6(3 \%)$ uses the network with other media platform that wasn't listed.

Table 11 further showed that 138(69\%) of the respondents accessed the wireless network through their smart phones, while $45(22.5 \%)$ used their personal laptops. Only $9(4.5 \%)$ and $8(4 \%)$ of the respondents used their desktop and table respectively to access the network. This shows that smart phones are the network device of choice in the rural community's mobile applications on smart phones will be more preferred compared to laptops in the rural communities. This is because phones are easier to manage in the communities in terms of cost, battery life and mobility. There is a tertiary institution located close to these communities.

Staff and students of the institution residing in the communities also use the network facilities. This explains the nature of users, devices and applications used. It also shows that the users find the network accessible, affordable and reliable. The educational landscape of these people and communities will be enhance to a higher quality as a result of the availability of the enhanced Wifi-based rural extension wireless network architecture.

Table 10: Social Media Platform

\begin{tabular}{|c|c|c|}
\hline Media Platform & Frequency & Percent \\
\hline Blackberry BBM & 77 & 38.5 \\
\hline Facebook & 95 & 47.5 \\
\hline Twitter & 11 & 5.5 \\
\hline Instagram & 11 & 5.5 \\
\hline Other & 6 & 3 \\
\hline Total & $\mathbf{2 0 0}$ & $\mathbf{1 0 0}$ \\
\hline
\end{tabular}


Table 11: Wireless Devices use

\begin{tabular}{|c|c|c|}
\hline Devices & Frequency & Percent \\
\hline Smartphone & 138 & 69 \\
\hline Laptop & 45 & 22.5 \\
\hline Desktop & 9 & 4.5 \\
\hline Tablet & 8 & 4 \\
\hline Total & $\mathbf{2 0 0}$ & $\mathbf{1 0 0}$ \\
\hline
\end{tabular}

\subsection{NETWORK SUSTAINABILITY}

Table 12 shows the measures set up and the actions taken to ensure that the wireless network continues to render the required services to the users without major disruptions or failures. The point-to-point network set up enable multiple client connection and more users can be given access to the network. This is to allow for additional equipment into the network as a result of the ptMP network design. Other measures like availability, security and manageability were also taken care of as described in Table 12.

Table 12: Network Validity Measures

\begin{tabular}{|c|c|c|}
\hline \begin{tabular}{|l|} 
Validation \\
measures
\end{tabular} & Action taken & Outcome/Results \\
\hline Scalability & $\begin{array}{l}\text { A point-to-point (PtMP) network was setup } \\
\text { that will allow multiple client AP to connect } \\
\text { to single AP thereby introducing full-duplex } \\
\text { speed i.e. transmit and receive uses separate } \\
\text { channels. }\end{array}$ & $\begin{array}{l}\text { The network is very robust and adding more } \\
\text { equipment is seemingly easy with the design of the } \\
\text { ptMP network architecture. This ensures the } \\
\text { extension of the network to cover more users. }\end{array}$ \\
\hline Availability & $\begin{array}{l}\text { The OSPF routing protocol setup at the } \\
\text { distribution layer enables the network to } \\
\text { easily recalculate a backup route in case there } \\
\text { is a downtime. The primary source of power } \\
\text { for all devices on the network is solar energy, } \\
\text { while the secondary source of power is from } \\
\text { the national grid. }\end{array}$ & $\begin{array}{l}\text { With this, the network down time is drastically } \\
\text { reduce and the equipment performance and } \\
\text { network availability is optimal. During the first one } \\
\text { year, very minimal downtime which cumulatively } \\
\text { has not exceeded } 12 \text { hours was recorded. }\end{array}$ \\
\hline Security & $\begin{array}{l}\text { Setup a proprietary device that will perform } \\
\text { authentication, authorization and access } \\
\text { control functions on the network. Each } \\
\text { wireless device was pass worded with an } \\
\text { MDS level of encryption and a radius server } \\
\text { was configured in the core layer to ensure } \\
\text { only authorized users gain access to the } \\
\text { network. }\end{array}$ & $\begin{array}{l}\text { The wireless network system since installation } \\
\text { have not recorded any security bridge during the } \\
\text { first one year. }\end{array}$ \\
\hline Manageability & $\begin{array}{l}\text { The Network Operating Centre was setup to } \\
\text { manage the entire network system and devices } \\
\text { and also monitor the traffic on the network. }\end{array}$ & $\begin{array}{l}\text { During the period in review, managing the network } \\
\text { has been very easy from the network centre. Issues } \\
\text { arising on the network are promptly reported } \\
\text { through the network monitoring software (Dude) } \\
\text { Very few issues were reported, such as bandwidth } \\
\text { bottleneck and was promptly resolved through } \\
\text { bandwidth shaping. }\end{array}$ \\
\hline
\end{tabular}

\section{CONCLUSION}

During the study, an enhanced Wifi-based wireless network architecture was designed and implemented to cover five rural locations. This was done by adapting and modifying the wireless fidelity based rural extension architecture proposed by [1] Patra (2011). This was achieved by carefully assessing the local environment and bringing the access points closer to the client premises equipment (CPE). Point-to-multipoint (PtMP) links were deployed in five communities 
with low user densities areas using off-the-shelf 802.11n MIMO chipset wireless equipment. The throughput monitor utility on the $802.11 \mathrm{n}$ equipment showed a high throughput received on the client premises equipment. The 802.11n MIMO point-to-multipoint network implemented at the access layer helped to reduced interference from obstacles within the environment. This increased the throughput of the network significantly and the network only had a loss of $0.5 \mathrm{Mbps}$ as against the $1.5 \mathrm{Mbps}$ adopted.

The network performance was high with high quality of service. The servers output on the number of users and data usage per month showed that an average bandwidth of $100 \mathrm{Mb}$ was possible for every user on daily basis. The results also showed that smart phones where the predominant devices used in accessing the network and the signal strength received by the users was high. The implementation of a wireless network in rural community was the best option to bring ICT services to such communities. Adequate strategies are required to deploy network infrastructures in rural communities. This is because of the environment and possible obstacles that can hinder network signal propagation like mountains and vegetation. These obstacles can increase the cost of installation if not properly handled. It was found during the study that the height at which antennas were placed determines the signal penetration on objects like walls. Also, the higher the radio, the farther the signal can travel, but the weaker it's penetrating power. The transmit/receive rate of the network was thrice as fast as Ethernet.

It was also shown during the study that instead of placing the outdoor access points on the base stations for client connection to the network. In the study, it was found that it was better to setup a $5 \mathrm{Ghz}$ wireless point-to-multipoint connection as indoor access point for high throughput and good quality of service. And using all $802.11 \mathrm{n}$ chipset radios, it was possible to achieve excellent performance on the network. The network was accessible to members of the communities, as well as teachers and students in the communities. Further work can be done to improve the architecture and network by implementing full-duplex option over the distributed network. This can be followed up with a study to find out the performance of the network over mobile applications that utilizes high bandwidth such as e-Health applications, mobile video-surveillance applications and e-Learning applications.

\section{REFERENCES}

[1] Divya Sargunarangan (2011). A Low-Cost Efficient Wireless Architecture for Rural Network Connectivity. Electronic Project. Copyright Classle. Retrieved from: https://www.cs.nyu.edu/ lakshmi/wire.pdf

[2] Nikos Korkakakis and Kyriakos Vlachos (2010). Building Wireless Metropolitan Networks.Research Academic Computer Technology Institute and Computer Engineering and Informatics Department, University of Patras.

[3] Du Bowei, Demmer Michael and Brewer Eric(2006). Analysis of WWW Traffic in Cambodia and Ghana. 15thinternational WWW Conference(May 2006). Edinburgh.

[4] Todd L. (2007).Cisco Certified Network Associate. 6th Ed, Wiley Publishing Inc., Indianapolis, Indiana.

[5] Noll, G. Roger (2000). Telecommunications reform in developing countries. In A. O. Kruger (Ed).Economic policy reform: The second stage. Chicago, University of Chicago Press.

[6] Flickenger, Rob., Aichele Corinna., Fonda Carlo., Forster Jim., Howard Ian., Krag Tomas., and Zennaro Marco. (2006). Wireless Networking in the Developing World. Limehouse Book Sprint Team, First Edition.

[7] Horst, Heather. and Miller, Daniel. (2006). The Cell Phone: An Anthropology of Communication.Berg, 2006.

[8] World Bank Report (2004). World Development indicators. Washington, DC: World Bank. 
International Journal of Computer Science \& Information Technology (IJCSIT) Vol 9, No 3, June 2017

[9] Wallsten, J. Scott. (2003). Regulation and Internet use in Developing Countries. Washington DC, AEI-BrookingsWiFi's Growing Pains (Special Report). 2004, February [8]Business Week Online.Retrieved May 18, 2005. (http://www.businessweek.com/technology/tc-speccial/tc-04wi.htm)

[10] Kumar Arun, RajputNitendra., Chakraborty Dipanjan., Argarwal, K. Sheetal. and Nanavati, A. A.(2007). WWWTW: The World-Wide Telecom Web. In: NSDR'09 Kyoto, Japan.

[11] Patel, Neil.,Chittamuru, Deepti., Jain, Anupam., Dave, Paresh. and Parikh S. Tapan (2010). AvaajOtalo - A Field Study of an Interactive Voice Forum for Small Farmers in Rural India. In: CHI'10, Atlanta, GA.

[12] Galperin, Herman. and Bar, Francois. (2004). Building the Wireless Internet Infrastructure: from cordless EthernetArchipelagos to Wireless grids. Communication and Strategies, 54(2), 45 -68.

[13] LitePoint (2012): LitePoint Introduces IQxel-The First 802.11ac Manufacturing Test Solution Accessedfrom:http://litepoint.com/press-releases/litepoint-introduces-iqxel-the-first-802-11acmanufacturing-test-solution/ (Accessed: March 12, 2015).

[14] IEEE (2007) Wireless LAN Medium Access Control (MAC) and Physical Layer (PHY) Specifications. IEEE Standard for Information Technology - Telecommunications and information exchange between Accessed from: http://www.ie.itcr.ac.cr/acotoc/Ingenieria/Lab\%20TEM\%20II/Antenas/Especificacion\%20802\%2011 -2007.pdf (Accessed April 20, 2015).

[15] SoneshSurana, Rabin K. Patra., Sergiu Nedevschi., Manuel Ramos., Lakshminarayanan Subramanian., Yahel Ben-David, Eric A. Brewer. (2008). Beyond Pilots: Keeping Rural Wireless Networks Alive. NSDI 8,119-132.

[16] Patra K. Rabin, Nedevschi Sergiu., SuranaSonesh., Sheth Anmol., LakshminarayananSubramanian , and Eric A.Brewer (2007): WiLDNet: Design and Implementation of High Performance WiFi Based Long Distance Networks. NSDI 1(1),1.

[17] Atel Electronics (2015): Wireless access point Airmax TDMA (Ubiquiti NanoStation M5)Accessed from: http://www.atel-electronics.eu/produkt.php?hash=07006 (Accessed: March 15, 2015).

\section{AUTHORS}

Okoro Osahon is an Electronic Engineer in the Department of Computer Science, University of Calabar. $\mathrm{He}$ is a Computer Networking expert with professional qualifications in CCNA. He holds a Master degree in Computer Science.

Edim Azom Emmanuel is a Computer Scientist and a Senior Lecturer in the Department of Computer Science, University of Calabar. He Holds an M.Sc. and Ph.D in Computer Science. 